IRA-International Journal of Applied Sciences ISSN 2455-4499; Vol.04, Issue 01 (2016)

Institute of Research Advances

http://research-advances.org/index.php/IRAJAS

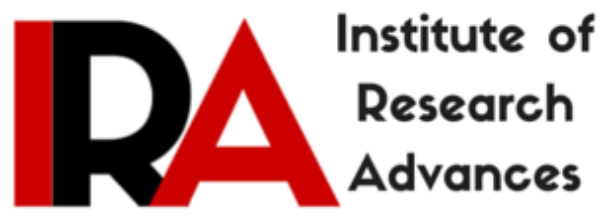

\title{
Eco-Friendly Bleaching of Soda-AQ Chemical Elephant Dung Pulp
}

Saleem, M. ${ }^{1}$, Yaqoob, N. ${ }^{1}$ and Rehman, I. Ur- ${ }^{2}$.

${ }^{1}$ Department of Environmental Science, Lahore Collage for Women University, Lahore, Pakistan.

${ }^{2}$ R. D. \& C. Department, Packages Limited, Lahore, Pakistan.

DOI: http://dx.doi.org/10.21013/jas.v4.n1.p4

How to cite this paper:

M., S., N., Y., \& I. Ur-, R. (2016). Eco-Friendly Bleaching of Soda-AQ Chemical Elephant Dung Pulp. IRA-International Journal of Applied Sciences (ISSN 2455-

4499), 4(1). doi:http://dx.doi.org/10.21013/jas.v4.n1.p4

(C) Institute of Research Advances

(cc) EY-NC

This works is licensed under a Creative Commons Attribution-Non Commercial 4.0 International License subject to proper citation to the publication source of the work.

Disclaimer: The scholarly papers as reviewed and published by the Institute of Research Advances (IRA) are the views and opinions of their respective authors and are not the views or opinions of the IRA. The IRA disclaims of any harm or loss caused due to the published content to any party. 


ABSTRACT
Elephant dung is an excellent source of cellulosic fibers that is a basic requirement for paper making.
In this study, bleaching was carried out by using eco-friendly bleaching agents such as sodium
percarbonate, oxone and hydrogen peroxide. Soda-anthraquinone (soda-AQ) semi-chemical and
chemical elephant dung pulps were bleached at varying doses of bleaching agents, bleaching aids and
reaction time. Presence of residual lignin after pulping stage was imparting brown color to the pulp
and hence was removed by subsequent bleaching stages. Soda-AQ chemical pulps was treated with
different multistage bleaching sequences. The results of this study showed that sodium percarbonate
and oxone could not achieve targeted brightness for elephant dung pulp samples. Whereas, using
three stage hydrogen peroxide bleaching sequence [AP $\left.P_{5} P_{3} P_{2}\right]$ helped to achieve the targeted
brightness $\sim 60.0 \%$ G.E without much sacrificing the other optical and physical properties of the
pulp. Eco-friendly bleaching helped to increase the beauty of the final product. Being rich in fiber,
elephant dung pulp has a potential to be blended with other raw materials to make hybrid exotic
papers of high market value.

Key Word: Elephant dung, cellulosic fibers, sodium percarbonate, oxone, hydrogen peroxide, TCF bleaching

\section{INTRODUCTION}

Paper is a versatile material and besides its tremendous use in writing and printing, it is extensively being used in packaging material, as a food ingredient and cleaning products in many cultures. As consumption of paper increases, deforestation also increases and therefore, there is an ultimate need for alternative raw materials used for paper production. This will not only meet the increasing demand for paper but also protect the forest and ultimately the environment.

Paper industry mostly depends on three major raw material sources: forest, e.g., hard wood (oak, walnut, maple, poplar and birch etc) and soft wood (pine, balsam, spruce and douglas fir); agricultural residues e.g., bagasse, cotton, rice, kahi, flax, kenaf, reed, wheat straw, banana, citrus fruits etc. and animal residues e.g., panda dung, cow dung, horse dung, donkey dung or elephant dung etc. [1-5]

For preventing deforestation, the paper industry will mostly depend on non-wood recourses in the coming years. In early twentieth century, there was $60 \%$ wood source for paper manufacturing, which has now been decreased up to $37 \%$. Many developed and developing countries are already using nonwood resources like in China, Sri Lanka, Thailand and Pakistan etc. during last few decades. The nonwood fibers have attracted the attention of many researchers to manufacture paper from exotic treefree materials such as kahi, reed, hemp, banana, cow dung, elephant dung etc. This approach will help to clean the environment by utilizing waste into useful paper products.

Elephant dung contains high proportion of fibrous material that makes it attractive to be used as a raw material for the manufacture of various grades of paper that can be used as art paper, cards, certificates, notebooks, gift papers and other paper products. Thailand is the first country to utilize elephant dung to manufacture paper while Sri Lanka is also making paper product from the dung. Dung collected per elephant on daily basis is enough to make 115 A4 sheets of paper. The color of paper is dependent on the elephant's diet which is in turn affected by the season. The paper is yellow when the elephant eats sugarcane and dark brown in colour when they eat jowar (sorghum) and bajra (pearl millet). Elephant dung when disposed off in the environment increases waste load, however, paper made from elephant dung is indeed special and innovative but to enhance its esthetic value, bleaching is vital.

According to Ulrich, 2010, from the last two centuries, bleaching has passed through many developmental processes [6]. The first century was learning process in which bleaching was carried out by chlorine and its derivatives. While in the second century many more compounds were introduced as bleaching agents. However the environmental impacts were of the major concern in second century. 
To get maximum and stabilized brightness, it is of key importance to remove lignin content from the pulp as much as possible to reduce its chromophoric contents. The bleaching agent solublized the chromophoric groups which were then removed during subsequent washing stage [7]. Conventional chlorinated bleaching agents are potential threats to our surrounding environment; therefore, in this work a total chlorine free bleaching (TCF) sequence was developed to bleach the elephant dung pulp.

\section{MATERIALS AND METHOD}

\section{Pulping of Elephant dung}

$\sim 7 \mathrm{Kg}$ of elephant dung on o.d basis (oven dried weight) was collected for this study. The raw material was then dried under the sun and was overturned occasionally by using wooden sticks to facilitate drying process and to minimize the chances of any microbial growth underneath. The samples were then oven dried at $105^{\circ} \mathrm{C}$ for 30 minutes and stored in air tight zip lock polyethylene bags at ambient temperature.

Semi-chemical and chemical pulping of the raw material was carried out in bulk in a closed loop rotary digester using the reaction conditions mentioned in table 1 . The pulp was then passed through \#40 mesh size screen to separate the uncooked material. The separated cooked fibrous pulp was then transferred into a defibrator to disintegrate the pulp at $3000 \mathrm{rmp}$ for 60 seconds. The disintegrated fiber was further passed through $0.15 \mathrm{~mm}$ slotted screen to remove the shives as much as possible. The screened pulp was then dewatered to high fiber consistency $>30.0 \%$ by manual pressing.

Various optical properties (brightness [8], opacity [9], whiteness and yellowness [10]), physical properties (burst index [11, tensile index [12] and tear index [13]) and chemical properties (kappa number [14] and $\alpha$-cellulose [15]) were studied prior to bleaching to investigate the effect of bleaching on the pulp during subsequent experimental trials.

\section{Sand removal}

Sand was removed through the process of decantation. The sample was added in a bucket full of water and stirred for a few minutes. The sand particles were allowed to settle at the bottom of bucket for 1015 min and then sample was carefully separated by decantation.

\section{Bleaching of Elephant dung pulp}

Prior to bleaching, the pulp was determined for its iron content [16] and then acidified with $2.0 \%$ of $4 \mathrm{~N}_{2} \mathrm{SO}_{4}$ on o.d. elephant dung pulp. The pulp was mixed thoroughly and continuously for efficient distribution of acid on the pulp fiber for $10 \pm 2.0$ minutes at room temperature $\left(25-26^{\circ} \mathrm{C}\right)$ at $10.0 \%$ consistency to remove its metal contents followed by washing to neutral $\mathrm{pH}$ and then pressed to dewater for consistency greater than $\sim 25 \%$ for easy storage at $4^{\circ} \mathrm{C}$ in polyethylene zip lock bags.

Various bleaching chemicals such as sodium percarbonate (S), sodium hypochlorite (H), EDTA (Q), hydrogen peroxide $(\mathrm{P})$ and oxone $(\mathrm{Ox})$ were investigated in various combinations and at varying reaction conditions of temperature, reaction time, consistency, alkali charge etc. to design an optimum bleaching sequence for soda-anthraquinone (Soda-AQ) elephant dung pulp (Table 2). As a result different multistage bleaching sequences were developed and their results were compared to study their effect on increasing the final bleach brightness with comparable pulp properties.

For each bleaching trial $30.0 \mathrm{~g}$ of o.d. acidified (A) elephant dung pulp was kept in polyethylene zip lock air tight bags and were placed in preheated temperature controlled water bath for 5-10 minutes until pulp attain the required temperature. The bleaching chemicals were then added into the pulp and mixed thoroughly for efficient distribution of bleaching reagents on pulp fibers. The reaction bags were then again kept into the water bath for the specified time of bleaching for each trial. At the end of each trial, reaction bag was immediately removed from the water bath and water was added to stop the bleaching reaction. The pulp was then washed with distilled water on \#200 mesh screen, pressed to dewater and stored in polyethylene bags at $4{ }^{\circ} \mathrm{C}$ either for next bleaching stage or testing

\section{RESULTS AND DISCUSSION}

Elephant dung is a nutrient rich material. If it was left untreated, there was a chance of immediate fungal and other microbial growth that can digest the useful fibers, and hence make the material nonuseable for paper making. Semi-chemical and chemical pulping was carried out by using soda-AQ 
pulping procedure where alkali charges varied from $10.0 \%$ to $14.0 \%$ on o.d.p. respectively. Anthraquinone has been found to be a very effective additive for alkaline pulping processes. It is a yellow highly crystalline solid, poorly soluble in water but soluble in hot organic solvents. The addition of anthraquinone to the process caused an increase in yield [17]. It worked as a redox catalyst when added to the digester. The effect of this redox reaction was to stabilize cellulose fibers by oxidation of the aldehyde groups of cellulose and speed up delignification through the breakage of bond of lignin. Hence, there would be less fiber consumption, reduced chemical charges, and lower energy usage, thus making the pulping process environmentally favorable for desirable qualities. Uni Dol was used as a surfactant, which act as a detergent in cooking process. Time and temperature was kept constant in both the trials (T I and T II). Literature revealed that increase in cooking temperature at very high chemical charges gives no improvement in bleachability for non-wood raw materials [1819]. The comparison of various properties showed better overall optical and physical properties in AQ-soda chemical pulp (TI) as compared to semi-chemical pulp (TII) (Table 3). Therefore, AQ-soda chemical pulp was chosen for bleaching trials.

\section{Determination and removal of metal content (A-Stage)}

Different metal contents in the pulp convert into metal hydroxides or metal sulphides, during cooking process, which are water insoluble and remain in the pulp sample [6]. Presence of metal ions in the pulp negatively affects the TCF bleaching action because TCF bleaching mostly carried out by oxidation and reduction process of different bleaching chemicals which are highly susceptible to metals ions. Hence these metal ions effects efficiency and selectivity of the bleaching process. Metals ions can be reduce by the process of acidification from $\mathrm{pH} 1.5-3.0$ [20]. Iron content of semichemical pulp and chemical pulp was determined to be $280.0 \mathrm{ppm}$ and $803.0 \mathrm{ppm}$ before acidification while after acidification it was found to be decreased to $210.0 \mathrm{ppm}$ and $455.0 \mathrm{ppm}$ respectively.

\section{Bleaching of acidified elephant dung pulp (A)}

For centuries the bleaching agent used for paper making was chlorine and its derivatives which helped to brighten the paper $>80 \%$ ISO. But chlorine and its derivative compounds have detrimental effects on the environment including lakes, rivers and seas etc. This work was carried out to study the application of eco-friendly total chlorine free (TCF) chemicals to bleach elephant dung pulp. Bleaching was also carried out with chlorinated chemical i.e., sodium hypochlorite to make comparison with TCF bleaching results. The TCF bleaching agent used to brighten the paper included sodium percarbonate, oxone and hydrogen peroxide. These bleaching chemicals were used in various combinations and under different reaction conditions to obtain the targeted brightness which was $>50$ $\%$ G.E (Figure 1 and Table 2)

Initially the soda-AQ pulp was bleached with sodium percarbonate. Different conditions were used for TCF bleaching like percarbonate variable dosage $(3.0 \%, 5.0 \%, 7.0 \%$ and $10.0 \%$ on o.d.p.), addition of chelating agent and varied reaction time. The Soda-AQ pulp was also bleached with sodium hypochlorite to get target brightness $>50.0 \%$ G.E. The addition of chelating agent (EDTA) with sodium percarbonate gave brightness up to > $30.0 \%$ G.E, which was lower than sodium hypochlorite bleaching agent. As the bleaching stages increases; the increase in brightness was also observed. The reason for this could be the residual lignin which was left after pulping process and imparts dark brown color to the handsheet. The bleaching agent helped to soften the lignin so it could be easily soluble in water and hence removed during washing stage. This helped to brighten the paper. The percarbonate bleaching agent did not improve the targeted brightness of $>50 \%$. Pulp was then bleached with two stage bleaching trials $\left[\mathrm{A}\left(\mathrm{S}_{5} \mathrm{Q}\right) \mathrm{P}_{5}\right]$ and $\left[\mathrm{AP}_{5} \mathrm{P}_{2}\right]$ and brightness $<48.0 \%$ G.E was obtained. Three stages bleaching trials with hydrogen peroxide in a sequence $\left[\mathrm{AP}_{5} \mathrm{P}_{3} \mathrm{P}_{2}\right]$ gave optimum brightness $\sim 60.0 \%$ G.E (Figure 1 ).

Lignin is the color imparting group in the pulp. Its structure consists of many carbon-carbon linkages between the unit; which make it very different to degrade the high molecular weight structure into low molecular weight structure to brighten the paper, hence, it is necessary to remove color imparting components [21]. The other approach is the lignin preserving bleaching where pulp is to whiten without removing the chromophoric groups in pulp structure. TCF bleaching with hydrogen peroxide 
behave as lignin preserving bleaching agent and was found to be effective to achieve the targeted brightness of the pulp. Also the TCF bleaching would be helpful to reduce the load of chlorinated compounds from the environment. During hydrogen peroxide bleaching, peroxide dissociated into perhydroxyl and hydronium ions. Perhydroxyl ion is the active bleaching component, which usually generates in high bleaching $\mathrm{pH}$. Hydronium ions initiate the formation of active bleaching agent and trigger hydrogen peroxide to whiten the pulp. Literature revealed that the effect of hydrogen peroxide in increasing brightness is more pronounced at pulp consistency $>25.0 \%$ [22-23]. High temperature during peroxide bleaching accelerates the bleaching process and boost up the final brightness of pulp. High reaction time $(60-120 \mathrm{~min}$.) lowers the chance of pulp yellowing [20]. These facts indicate that suitability of bleaching conditions used for the current study.

The physical and optical properties were also studied for all bleaching trials (Figure 2). It was observed as the dose of sodium percarbonate increases, the physical properties (tear, burst and tensile indices) of hand sheet also improved. The reason was that the physical properties of cellulosic fibers arise from inter-fiber bonding. These bonds help to hold the fibers together and hence increase the strength of the paper. Cellulose and lignin plays important role in inter-fiber bonding. Lignin acts as a barrier between the cellulose fiber and does not allow it to bind easily. When the lignin is removed, the barrier between the cellulosic fiber finishes and developed strong hydrogen bond among them and hence the strength of the handsheets improved.

\section{CONCLUSION}

Bleaching is necessary to enhance the esthetic value and quality of the paper made from elephant dung pulp. TCF bleaching is an environmental friendly approach. To bleach elephant dung, acidified elephant dung pulp was bleached in three consecutive hydrogen peroxide bleaching stages $\left[\mathrm{AP}_{5} \mathrm{P}_{3} \mathrm{P}_{2}\right]$ with brightness $\sim 60.0 \%$ G.E with comparable strength properties as compared to bleaching of pulp with conventional and toxic sodium hypochlorite bleaching.

\section{Acknowledgement}

We acknowledge the support of Dr. Amir Said, Manager, R, D and C Department, Packages Limited, Mr. Shafqat Ali, Director of Lahore Zoo, Mr. Younus Maseeh, Mahot at Lahore Zoo, Pakistan during this study.

\section{REFERENCES}

1. Nadeem, F., Moazzam, A., Yaqoob, N. and Rehman, I., 2014. Processing of Elephant Dung and its Utilization as a Raw Material for making exotic paper, Research Journal of Chemical Sciences, 4(8): 94-103

2. Kamoga, O. L. M., Byaruhanga, J. K,and Kirabira, J. B., 2013. A Review on Pulp Manufacture from Non Wood Plant Materials, International Journal of Chemical Engineering and Applications, 4 (3)

3. Read, L. "Fibre supply outlook for North America", 1995. Proceedings of Tappi Global fibre supply symposium, Tappi press, Atlanta G. A. pp. 19

4. McClosekey, J. T., "What about Non wood?" 1995. Proceedings of Tappi Global fibre supply symposium, Tappi Press, Atlanta, GA, USA, pp. 95

5. Hurter, R. W., 2001. Non-wood plant fiber uses in paper making short course notes extracted from Agricultural residues, Tappi J., Ottawa Ontario, Canada.

6. Suss, H. U., Eul, W. and Helmling, O. 1989, Semi Bleaching of Kraft pulp using oxygen and hydrogen peroxide, Journal of Papier 47(3): 318-232.

7. Yaqoob, N., Stack, K., Cheema, K. J. and Mateen, B and. Rehman, I. Ur-. 2011. Oxidative Delignification and Bleaching of Alkaline Sulphite-Anthraquinone Wheat Straw Pulp,Asian Journal of Chemistry, 23 (7): 2845-2851.

8. T 452 om-08, 2008. Brightness of pulp, paper and board. TAPPI. USA

9. T 425 om-11, 2011. Opacity of paper. TAPPI. USA

10. ASTM E313, 2012. Standard Practice for Calculating Yellowness and Whiteness Indices from Instrumentally Measured Color Coordinates. American Society for Testing and Materials. USA. 
11. $\mathrm{T} 403$ om-02, 2008. Burst index of paper and paperboard. TAPPI. USA

12. $\mathrm{T} 404 \mathrm{~cm}-92,1992$. Tensile strength of paper. TAPPI. USA

13. T 414 om-88, 1998. Internal Tearing Resistance of paper. TAPPI. USA

14. T 236 om-06, 2006. Determination of Kappa number. TAPPI. USA

15. T $203 \mathrm{~cm}-99$, 2009. Alpha-, Beta- and Gamma- cellulose in Pulp. TAPPI. USA

16. $\mathrm{T} 266$ om-06, 2006. Iron Determination. TAPPI. USA

17. Appleton, Wisconsin. 1978. Anthraquinone/alkali pulping, The institute of paper chemistry. ( "Anthraquinone / Alkali Pulping - A Literature Review" (pdf). Project 3370. Appleton, Wisconsin: The Institute of Paper Chemistry. 1978-07-05.)

18. Sjöström, K. 1998., Kraft cooking with varying alkali concentrations - Influence on TCFbleachability, Journal of Nordic Pulp Paper Res. 13(1): 57-63.

19. Sjöström,K. 1999. Influence of ionic strength on kraft cooking and subsequent TCF-bleaching. Journal of Nordic Pulp Paper Res. 14(3): 226-230.

20. Bajpai, P. 2005. Environmentally benign approaches for pulp Bleaching, $1^{\text {st }}$ ed, Elsevier, Amsterdam, Netherland. pp: 85-86.

21. Crawford, L. 1981. Lignin biodegradation and transformation, New York: John Wiley and Sons. USA

22. Ackermann, C. 2000. Bleaching of deinked pulp, Recycled Fiber and Deinking-papermaking Science and Technology, Gottsching, L.D. and Pekarinen, H. Helsinki, Finland. pp: 307.

23. Renders, A. 1995. Recycled fiber bleaching. Technology of Paper Recycling, McKinney, Blackie Academic and Professional, Glasgow, UK. pp. 157. 
(Tables \& Figures)

Table 1 Pulping conditions for different experimental trial

\begin{tabular}{lcc}
\hline & \multicolumn{2}{c}{ Pulping Trials } \\
\cline { 2 - 3 } Pulping Conditions & Semi-chemical pulping & Chemical pulping \\
\cline { 2 - 3 } & 10.0 & T II \\
\hline NaOH Charge (\% on o.d. fiber) & 0.5 & 14.0 \\
AQ Charge (\% on o.d. fiber) & 0.1 & 0.5 \\
Uni Dol Surfactant (\% on o.d. fiber) & $7.0-7.5$ & 0.1 \\
Pressure (bar) & 10.0 & $6.0-7.0$ \\
Consistency (\%) & $150-165$ & 10.0 \\
Maximum temperature $\left({ }^{\circ} \mathrm{C}\right)$ & $45 \pm 2.0$ & $150-165$ \\
Time to maximum temperature (min.) & & $60 \pm 2.0$ \\
\hline
\end{tabular}

Table 2 Bleaching conditions used in various stages of different bleaching sequences

\begin{tabular}{|c|c|c|c|}
\hline Bleaching & \multicolumn{3}{|c|}{ Bleaching stages with experimental conditions } \\
\hline$\left[\mathrm{AS}_{5}\right]$ & \multicolumn{2}{|c|}{$\begin{array}{l}\mathrm{A} \\
4 \mathrm{~N} \mathrm{H}_{2} \mathrm{SO}_{4}=2.0 \% \\
\text { Temperature }=25-26^{\circ} \mathrm{C} \\
\text { Consistency }=10 \%\end{array}$} & $\begin{array}{l}\mathrm{S}_{5} \\
\mathrm{~S}=5.0 \% \\
\text { Consistency }=15 \% \\
\text { Temperature }=90-95^{\circ} \mathrm{C} \\
\text { Time }=60 \mathrm{~min}\end{array}$ \\
\hline$\left[\mathrm{AS}_{5}^{\prime}\right]$ & \multicolumn{2}{|c|}{$\begin{array}{l}\mathrm{A} \\
4 \mathrm{~N} \mathrm{H}_{2} \mathrm{SO}_{4}=2.0 \% \\
\text { Temperature }=25-26^{\circ} \mathrm{C} \\
\text { Consistency }=10 \%\end{array}$} & $\begin{array}{l}\mathrm{S}_{5}{ }^{\prime} \\
\mathrm{S}=5.0 \% \\
\text { Consistency }=15 \% \\
\text { Temperature }=90-95^{\circ} \mathrm{C} \\
\text { Time }=120 \mathrm{~min}\end{array}$ \\
\hline$\left[\mathrm{A}\left(\mathrm{S}_{5} \mathrm{Q}\right)\right]$ & \multicolumn{2}{|c|}{$\begin{array}{l}\mathrm{A} \\
4 \mathrm{~N} \mathrm{H}_{2} \mathrm{SO}_{4}=2.0 \% \\
\text { Temperature }=25-26^{\circ} \mathrm{C} \\
\text { Consistency }=10 \%\end{array}$} & $\begin{array}{l}\left(\mathrm{S}_{5} \mathrm{Q}\right) \\
\mathrm{S}=5.0 \% \\
\text { EDTA }=0.5 \% \\
\text { Consistency }=15 \% \\
\text { Temperature }=90-95^{\circ} \mathrm{C} \\
\text { Time }=60 \mathrm{~min}\end{array}$ \\
\hline$\left[\mathrm{A}\left(\mathrm{S}_{5} \mathrm{Q}\right) \mathrm{P}_{5}\right]$ & $\begin{array}{l}\mathrm{A} \\
4 \mathrm{~N} \mathrm{H}_{2} \mathrm{SO}_{4}=2.0 \% \\
\text { Temperature }=25- \\
26^{\circ} \mathrm{C} \\
\text { Consistency }=10 \%\end{array}$ & $\begin{array}{l}\left(\mathrm{S}_{5} \mathrm{Q}\right) \\
\mathrm{S}=5.0 \% \\
\text { EDTA }=0.5 \% \\
\text { Consistency }=15 \% \\
\text { Temperature }=90- \\
95^{\circ} \mathrm{C} \\
\text { Time }=60 \mathrm{~min}\end{array}$ & $\begin{array}{l}\mathrm{P}_{5} \\
\mathrm{P}=5.0 \% \\
\mathrm{NaOH}=2.0 \% \\
\mathrm{Na}_{2} \mathrm{SiO}_{3}=2.0 \% \\
\mathrm{Consistency}=15 \% \\
\text { Temperature }=90-95^{\circ} \mathrm{C} \\
\text { Time }=60 \mathrm{~min}\end{array}$ \\
\hline$\left[\mathrm{A} \mathrm{P}_{5} \mathrm{P}_{2}\right]$ & $\begin{array}{l}\mathrm{A} \\
4 \mathrm{~N} \mathrm{H}_{2} \mathrm{SO}_{4}=2.0 \% \\
\text { Temperature }=25- \\
26^{\circ} \mathrm{C} \\
\text { Consistency }=10 \%\end{array}$ & $\begin{array}{l}\mathrm{P}_{5} \\
\mathrm{P}=5.0 \% \\
\mathrm{NaOH}=2.0 \% \\
\mathrm{Na}_{2} \mathrm{SiO}_{3}=2.0 \% \\
\text { Consistency }=15 \% \\
\text { Temperature }=90- \\
95^{\circ} \mathrm{C} \\
\text { Time }=60 \mathrm{~min}\end{array}$ & $\begin{array}{l}\mathrm{P}_{2} \\
\mathrm{P}=2.0 \% \\
\mathrm{NaOH}=1.0 \% \\
\mathrm{Na}_{2} \mathrm{SiO}_{3}=1.0 \% \\
\text { Consistency }=15 \% \\
\text { Temperature }=90-95^{\circ} \mathrm{C} \\
\text { Time }=60 \text { min. }\end{array}$ \\
\hline
\end{tabular}




\begin{tabular}{|c|c|c|c|c|}
\hline [AOxEP] & $\begin{array}{l}\mathrm{A} \\
4 \mathrm{~N} \mathrm{H}_{2} \mathrm{SO}_{4}=2.0 \% \\
\text { Temperature }=25- \\
26^{\circ} \mathrm{C} \\
\text { Consistency }=10 \%\end{array}$ & $\begin{array}{l}\text { Ox } \\
\text { Ox }=0.5 \% \\
\mathrm{NaOH}=1.5 \% \\
\text { EDTA }=0.5 \% \\
\text { Consistency }=15 \% \\
\text { Temperature }= \\
65^{\circ} \mathrm{C} \\
\text { Time }=60 \mathrm{~min}\end{array}$ & $\begin{array}{l}\mathrm{E} \\
\mathrm{NaOH}=1.5 \% \\
\text { Consistency }=15 \% \\
\text { Temperature }= \\
65^{\circ} \mathrm{C} \\
\text { Time }=120 \mathrm{~min}\end{array}$ & $\begin{array}{l}\mathrm{P} \\
\mathrm{P}=2.0 \% \\
\mathrm{NaOH}=1.0 \% \\
\mathrm{Na}_{2} \mathrm{SiO}_{3}=1.0 \% \\
\text { Consistency }=15 \% \\
\text { Temperature }=90- \\
95^{\circ} \mathrm{C} \\
\text { Time }=60 \mathrm{~min}\end{array}$ \\
\hline$\left[\mathrm{AP}_{5} \mathrm{P}_{3} \mathrm{P}_{2}\right]$ & $\begin{array}{l}\mathrm{A} \\
4 \mathrm{~N} \mathrm{H}_{2} \mathrm{SO}_{4}=2.0 \% \\
\text { Temperature }=25- \\
26^{\circ} \mathrm{C} \\
\text { Consistency }=10 \%\end{array}$ & $\begin{array}{l}\mathrm{P}_{5} \\
\mathrm{P}=5.0 \% \\
\mathrm{NaOH}=2.0 \% \\
\text { Consistency }=15 \% \\
\text { Temperature }=90- \\
95^{\circ} \mathrm{C} \\
\text { Time }=120 \mathrm{~min}\end{array}$ & $\begin{array}{l}\mathrm{P}_{3} \\
\mathrm{P}=3.0 \% \\
\mathrm{NaOH}=1.5 \% \\
\text { Consistency }=15 \% \\
\text { Temperature }=90- \\
95^{\circ} \mathrm{C} \\
\text { Time }=120 \mathrm{~min}\end{array}$ & $\begin{array}{l}\mathrm{P}_{2} \\
\mathrm{P}=2.0 \% \\
\mathrm{NaOH}=1.0 \% \\
\text { Consistency }=15 \% \\
\text { Temperature }=90- \\
95^{\circ} \mathrm{C} \\
\text { Time }=120 \mathrm{~min}\end{array}$ \\
\hline$[\mathrm{AH}]$ & \multicolumn{2}{|c|}{$\begin{array}{l}\mathrm{A} \\
4 \mathrm{~N} \mathrm{H}_{2} \mathrm{SO}_{4}=2.0 \% \\
\text { Temperature }=25-26^{\circ} \mathrm{C} \\
\text { Consistency }=10 \%\end{array}$} & \multicolumn{2}{|l|}{$\begin{array}{l}\mathrm{H} \\
\mathrm{H}=6 \% \\
\text { Consistency }=10 \% \\
\text { Temperature }=60^{\circ} \mathrm{C} \\
\text { Time }=120 \mathrm{~min}\end{array}$} \\
\hline
\end{tabular}

Table 3 Comparison of mean optical and physical properties of handsheets made from elephant dung pulp of Trail I and Trail II

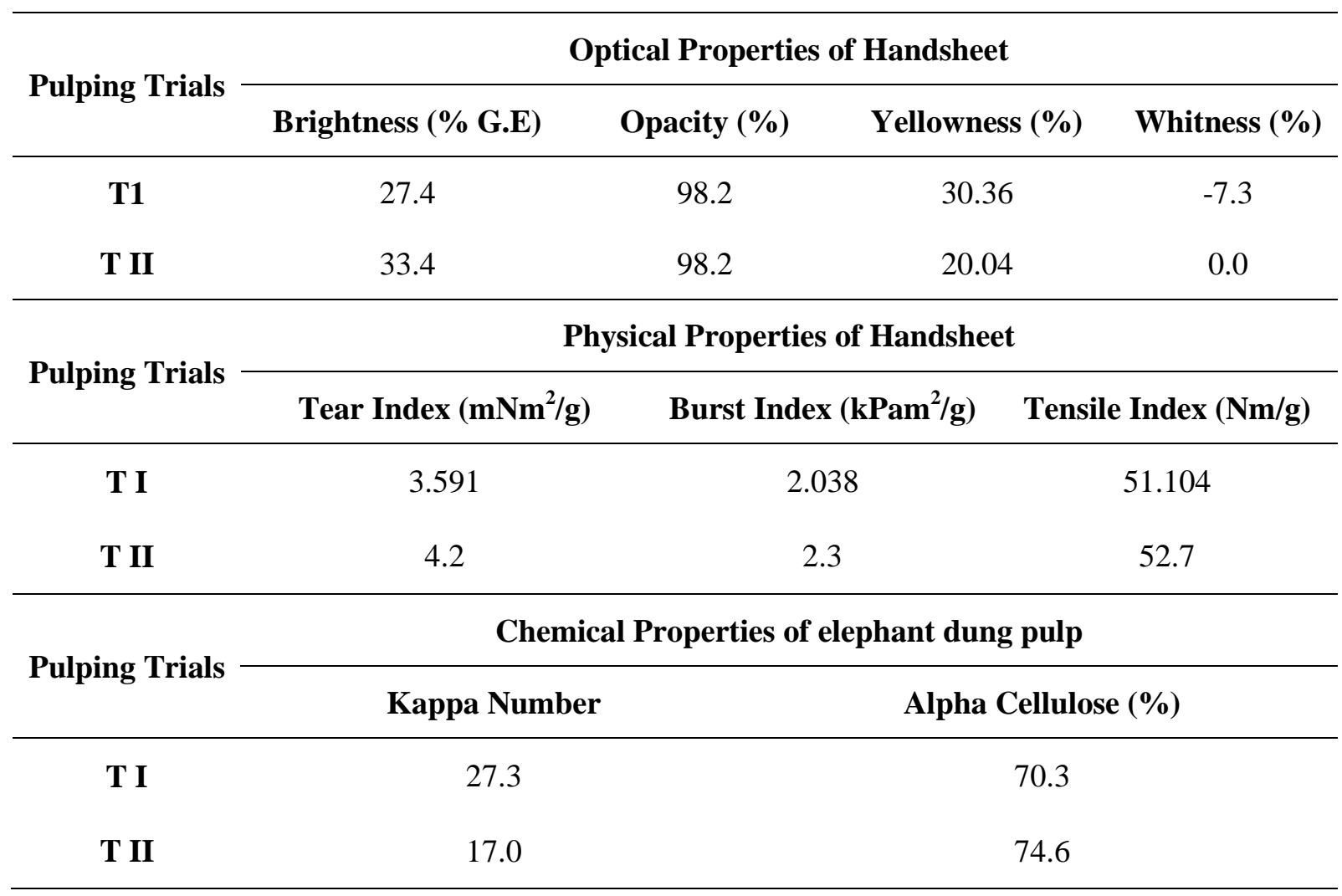




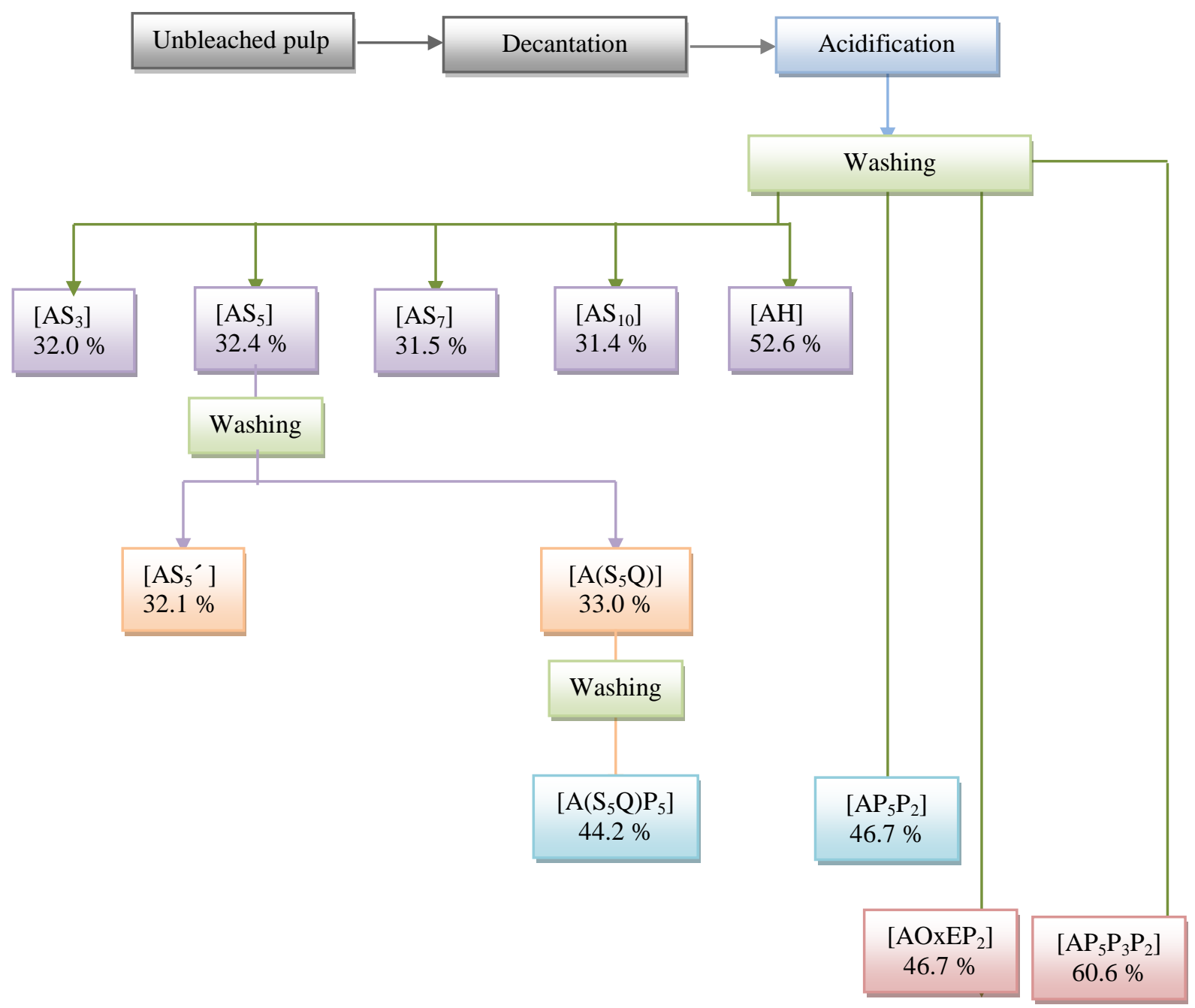

Figure 1 Designing of multistage bleaching sequences

(\% values represent brightness (\% G.E) of handsheets bleached in a particular bleaching sequence)

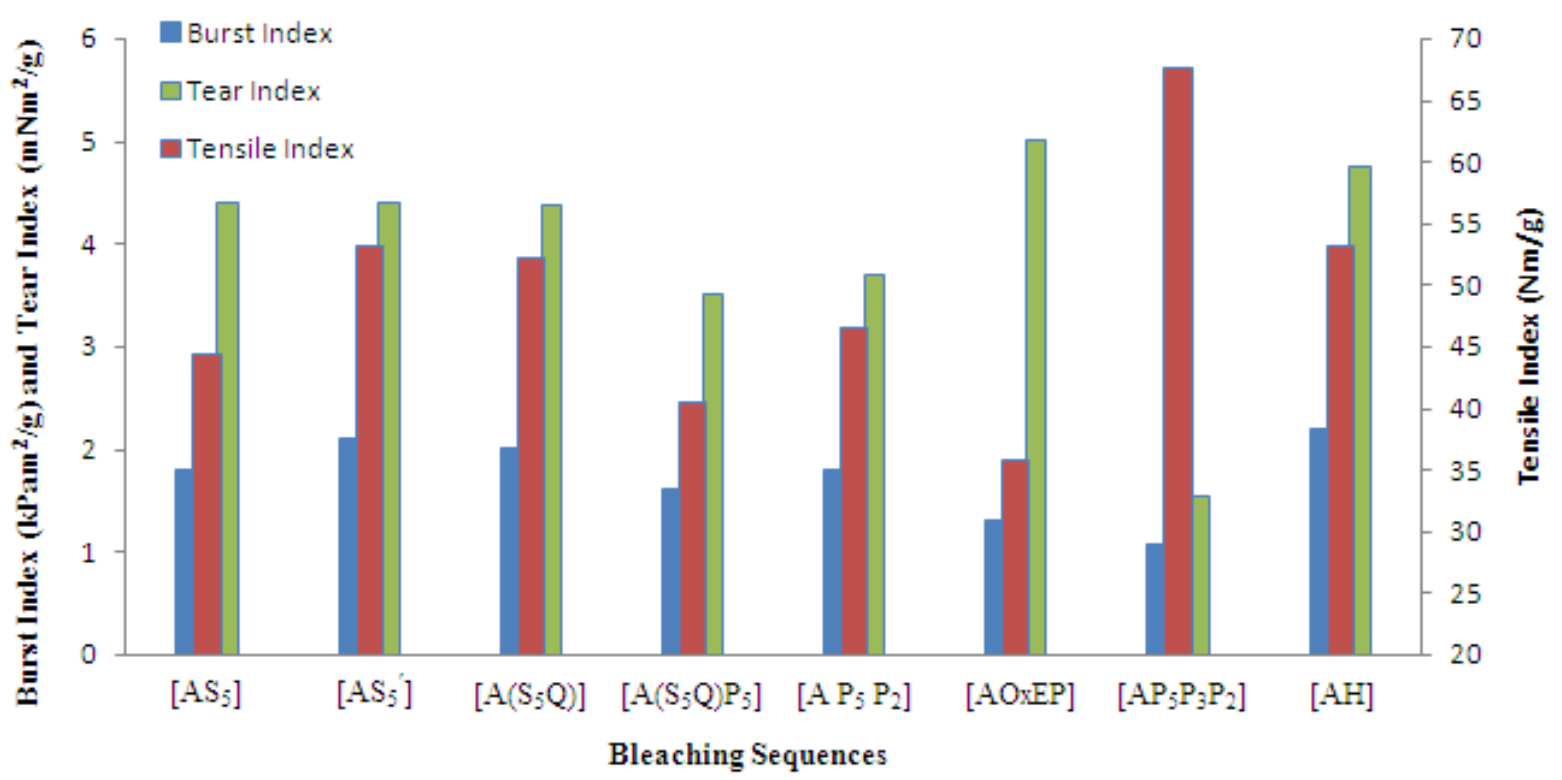

Figure 2 Strength properties of handsheets bleached with various multistage bleaching sequences. 